\title{
Client Consummation and Commitment on JIO Mobile Network in Vellore District: An Economic Analysis
}

\author{
Yoganandham Govindharaj*, Elanchezhian Govindasamy, Govindaraj Arumugam \\ Department of Economics, Thiruvalluvar University, Serkkadu, Vellore, India \\ Email: *drgyoga@gmail.com
}

How to cite this paper: Govindharaj, Y., Govindasamy, E., \& Arumugam, G. (2021). Client Consummation and Commitment on JIO Mobile Network in Vellore District: An Economic Analysis. Journal of Human Resource and Sustainability Studies, 9, 122-133.

https://doi.org/10.4236/jhrss.2021.91009

Received: February 12, 2021

Accepted: March 16, 2021

Published: March 19, 2021

Copyright $\odot 2021$ by author(s) and Scientific Research Publishing Inc. This work is licensed under the Creative Commons Attribution International License (CC BY 4.0).

http://creativecommons.org/licenses/by/4.0/

(c) (i) Open Access

\begin{abstract}
Over the past few years, the Indian mobile market has documented an exponential growth that has topped the authority's projections. Client Consummation is a measurement of consumer attitudes regarding products, services and products. Consumer Loyalty comprises of loyalty manners which is the act of customers making repeat purchases of current brands, rather than selecting competitor products. Client Constancy in Indian Mobile Telecommunication Services Sector Marketing Indian companies has been forced to adopt superiority organization platforms. Client consummation and future purchase purposes. Hostility in the broadcastings world in India is precise firm product moving of customers is also very high. That's why each provider trying to provide the best for its customers so that they can be loyal to the same provider. Customer loyalty is defined as a relationship between customer with a particular brand name, and company exemplified by their purchase of the customer or consumer buying behavior towards a consistent and profitable brand and measured as recommended to other consumers. In India, there are ten mobile telecom providers operating in the market. The main aim of this research is to study the Client Consummation and Commitment on JIO Mobile Network in Vellore District of Tamil Nadu in Economic perspectives. The foundation of this study is to know the customer loyalty of JIO customers towards JIO after free services time was over. The research question stated for the study is, whether customers are continuing the JIO mobile network or not? To know overall consummation of clienteles towards services of JIO mobile network, what are the factors which considered selecting JIO mobile network? This research paper is purely based on the primary survey conducted in the study area with help of pre-determined and well-structured interview schedule. The area of the study is Vellore District of Tamil Nadu. The sample size for this research paper is determined as 80 households in the study area.
\end{abstract}




\section{Keywords}

Indian Mobile Market, Customer Satisfaction, Services and Brands, Purchases of Current Brands, Tele Communication Services, Customer Satisfaction, Particular Brand Name

\section{Introduction}

The Indian telecom commercial is the World's wildest rising telecom industry. It is correspondingly the subsequent principal telecommunication network, In terms of number of wireless connection after china. Cellular service can be divided into two categories. They are the Global System for Mobile Communication (GSMC) and the Code Division Multiple Access (CDMA). The GSMC sector is dominated by JIO and some other networks. The ITU (International Telecommunication Union) demands quality requirement on the collective behavior of one or more objects. It is basically the level of guaranteed service to the client's consummation that favors the product.

In India, stiff competition advanced technology and reduced tariff have propelled the growth of mobile service in India. In the last five years, the industry had registered the markable growth in terms of whom these electronic gadgets are a major source for gaming, getting information, shopping, banking, entertainment and much more. This is the main reason why the Indian mobile service provided (MSP) market is overcrowded.

\subsection{Statement of the Problem}

This is an age of invention and innovation. The client whose beliefs and attitudes are dynamic should be satisfied with the product of their choice. It is needless to say that marketing is a new way of thinking about how consequences and their organization can change with target client, who is always inclined in seeking to satisfy his needs or the wants.

In utilizing the vast telecom market available in Vellore District services providers venture in the promotional activities, rather than focusing on specific services targeted at a particular segment of clienteles. In order to justify a service provision strategy, it is imperative to ascertain that the services that are provided are preferred and desirable by the client. Kim and others have analyzed that the client favorite would be the most important factor in determining business success.

Therefore, the market strategies and policies for promoting mobile service are to be mapped out, based on client needs and favorite. This study has been conducted to identify the reason for client dissatisfaction relating to mobile network service provider in Vellore District.

\subsection{Objectives of the Study}

The objectives of the study are to ascertain Client Consummation and Com- 
mitment on JIO Mobile Network in Vellore District of Tamil Nadu. The specific objectives are:

- To study the profile of JIO mobile network users in Vellore District.

- To ascertain and enumerate the service details of JIO mobile network in the study area.

- To analyses the influence of demographic factors and service details of clienteles on their product favorite and customer consummation.

\subsection{Importance of the Study}

The rationale for the existence of community service organizations is to meet the needs of the clienteles because the clienteles have the right to tap the mobile network.

- Product favorite are the vital rungs in the ladder of client Favorite and consummation.

- Organizations that strive beyond minimum standards and exceed the expectations of their clienteles are likely to be leaders in their sector.

\section{Review of Literature}

Akroesh et al. (2010) suggested that consumer attributes, brand images and awareness are the antecedents of brand preferences. Different factors such as brand, price, premiums, packaging, habits, guarantees, recommendation by family, friends and experts, advertising and display novelty, special characteristics of the manufactures can influence consumer's brand choices.

Jyothsna and Mahalakshmi (2015) revealed that all the core factors which are considered in this research (tariff rates, service quality, service availability, promotions and brand image) have a significant influence on the customers.

Vijay and Krishnaveni (2017) focused on portable mobile handset system subscriber level of fulfillment and which are the issues they had disappointment as well as to locate out the connection between demographic factors and level of satisfaction.

Mathiraj, Geeta, \& Saroja Devi (2019) elucidated that the measuring of the pull and push factors which influence portage and recognize the degree of portability achievement in the middle of diverse group of clientele.

Ambani (2020) asserted that the Reliance JIO 5G network will be powered by indigenous-developed network, hardware and technology components. As the digitalisation of the Indian economy and Indian society picks up speed, the demand for digital hardware will grow enormously.

Abbas (2021) stated that Industry, led by incumbents Bharti Airtel and Vodafone Idea, has been demanding rationalisation of taxes and levies since long, saying a relief would further enable them to spend more on deploying infrastructure. He further stated that there is a need to encompass reduced license fees from 3 percent to 1 percent, for all the TSPs, and also as an industry, need to 
have the spectrum usage charge reduced by 3 percent for all three telecom service providers.

\section{Hypotheses}

To fulfill the objectives of the study, following null hypotheses (Ho) were developed and tested with appropriate statistical tools.

- There is no significant association between gender, age, education, occupation, income and marital status with product favorites.

- There is no significant relationship between age, gender, education, occupation, income and marital status with client consummation.

\section{Research Methodology}

This research paper is based on descriptive and diagnostic study. This research depends primarily on the data collected through a well-framed and structured interview schedule to draw out the well-considered opinions of the respondents. Multi-stage random sampling procedures are adopted to get the answers from the customers on Client consummation and Commitment on JIO Mobile Network in Vellore District of Tamil Nadu. This study employs both analytical and descriptive type of methodology. The study is conducted in two stages format. In the first stage primary survey was conducted for gathering primary data and in the second stage, Journals articles, research papers, magazines, publications, unpublished reports, books, dailies, periodicals, websites, annual reports, manuals and booklets are collected for the purpose of gathering secondary sources of information relating to the theme of the paper. After identifying the study area, the researcher directly visits the study area for gathering data for the study with the help of pre-determined and well-structured interview schedule. The area of the study is Vellore District of Tamil Nadu. The sample size for this research paper is determined as 80 households in the study area.

\section{Latest Telecom Subscriber}

Reliance JIO Infocomm outpaced the other two operators to become the top mobile carrier in the country with 376.57 million subscribers, followed by Sunil Mittal-led BhartiAirtel with 142.34 million and Vodafone Idea, at the third spot, with 117.93 million subscriber base as on January 31, 2020, according to the attest telecom subscriber data collated by the Telecom Regulatory Authority of India.

Soon after the lockdown was imposed in the wake of the novel corona virus pandemic, telecom operators had announced extending the prepaid validity for their low-income subscribers till April 17 and further to May 3 on the subsequent announcement of lockdown extension. Telcos such as Airtel and Vodafone Idea credited Rs 10 talk time as credit for prepaid users while Reliance JIO credited 100 minutes of free talk time and 100 text messages for its entire user base. 


\section{Data Analysis and Interpretation}

Demographic information is imperative as it presents a profile of the entire sample taken for the study and represents a fundamental approach to the understanding of clienteles using JIO mobile network. In particular, the pilot study revealed the following Variables maintained their proximity with the dependent factors Age, gender, educational level, occupation, income, marital status. The conglometre of demographic and organizational profile is considered as independent Variables.

\subsection{Gender of the Respondents}

The study on gender based orientation towards product favorite and client consummation plays an important role. In fact, most of the behavioral studies have identified the significant differences between the opinion of male and female customers using JIO mobile network. In this study, the sample units execute the following frequency distribution of the gender.

From the sample taken for the study, it is found from the below Table 1 that 60 percent male respondents and 40 percent of females are using JIO mobile network. Therefore it is found that maximum of males are using JIO mobile network.

\subsection{Age of the Respondents}

Age is a crucial factor which depicts the personal and psychological maturity of the individuals. On the basis of the age, the customers using JIO mobile network are grouped under four heads, namely, below 20 years of age, 21 to 30 years, 31 to 40 years and above 40 years. In general Age of the respondents expose their maturity in understanding and selecting the best mobile network. In this analysis, the responses acquired from the various age groups of customers using JIO mobile network are depicted below Table 2 .

Table 1. Gender of the respondent.

\begin{tabular}{cccc}
\hline Gender & Frequency & Percentage & Cumulative Percentage \\
\hline Male & 48 & 60.00 & 60.00 \\
Female & 32 & 40.00 & 100.00 \\
Total & 80 & 100.00 & \\
\hline
\end{tabular}

Source: Primary data.

Table 2. Age of the respondent.

\begin{tabular}{cccc}
\hline Age & Frequency & Percentage & Cumulative Percentage \\
\hline Below 20 & 15 & 18.75 & 18.75 \\
$21-30$ & 25 & 31.25 & 50.00 \\
$31-40$ & 22 & 27.50 & 77.50 \\
Above 40 & 18 & 22.50 & 100.00 \\
Total & 80 & 100.00 & \\
\hline
\end{tabular}

Source: primary data. 
It is analyzed from different ages of respondents taken for the study that 27.50 percent in the age group 31 - 40 years, 31.25 percentage group 21 to 30 years, 20.50 percent above 40 years and only a minimum of 18.75 percent below 20 years prefer using JIO mobile network.

\subsection{Educational Qualification of the Respondents}

The level of education attained also influences the behavior of a consumer during their decision making process for buying the mobile networks. Consumers with higher education levels are often more responsive to technical and scientific appeals, prefer informative ads and are better able to judge the relationship between the price and quality of a mobile network. The following frequency Table 3 explains the different qualification possessed by the customers using JIO mobile network.

It is inferred from the below Table 3 that maximum of 31.25 percent are graduates using JIO mobile network, 22.50 percent are postgraduates, 18.50 percent are higher secondary, and 12.50 percent are SSLS qualified. Therefore maximum of respondents using JIO mobile network are graduates.

\subsection{Occupation of the Respondents}

Occupation or profession of a person influences buying behavior. The lifestyles and buying considerations and decisions differ widely according to the nature of the occupation. The following frequency Table 4 explains customers using JIO and their different occupations.

Table 3. Educational qualification of the respondent.

\begin{tabular}{cccc}
\hline Education & Frequency & Percentage & Cumulative Percentage \\
\hline SSLC & 10 & 12.50 & 12.50 \\
Higher & 15 & 18.75 & 31.25 \\
Graduate & 25 & 31.25 & 62.50 \\
Post graduate & 18 & 22.50 & 85.00 \\
Others & 12 & 15.00 & 100.00 \\
Total & 80 & 100.00 & \\
\hline
\end{tabular}

Source: primary data.

Table 4. Occupation of the respondents.

\begin{tabular}{cccc}
\hline Occupation & Frequency & Percent & Cumulative Percent \\
\hline Student & 08 & 10.00 & 10.00 \\
Home maker & 12 & 15.00 & 25.00 \\
Professional & 19 & 23.75 & 48.75 \\
Self-employed & 17 & 21.25 & 70.00 \\
Govt/Pvt. Employed & 14 & 17.50 & 87.50 \\
Unemployed & 10 & 12.50 & 100.00 \\
Total & 80 & 100.00 & \\
\hline
\end{tabular}

Source: Primary data. 
It is analyzed that 23.75 percent of professionals, 21.25 percent self-employed, 10 percent of students prefer using JIO mobile network. The further study revealed that 15 percent of homemakers, 17.50 percent of the Government and Private employed and 12.50 percent of unemployed also prefer using JIO mobile network.

\subsection{Income of the Respondents}

The Monthly income has an important bearing on the mobile network purchases. The buying behavior of customers will be highly influenced by the disposable income in their hands. The increase of competition on the mobile market in India has resulted in downfall of prices of mobile networks and has increased the buying behavior of mobile network purchases among the customers in Vellore District. The following frequency Table 5 explains the different incomes earned by the customers using JIO mobile networks.

It is found that 32.50 percent of the respondents earning a monthly income of Rs. 20,001 above 25 percent earning Rs. 10,001 to Rs. 15,000 17.50 percent earning income between Rs. 15,001 to Rs. 20,000, 13.75 percent earning between Rs. 5001 to 10,000 and only a minimum of 11.25 percent earning less than Rs. 5000 prefer using JIO mobiles network. Therefore maximum of respondents earning a monthly income of Rs. 20,001 and above favor this network.

\subsection{Marital Status of the Respondents}

Some interesting studies have pointed out that married customers have more usage of mobile networks compared to unmarried customers as they have more responsibility both personal and official. The customers using JIO mobile network are classified based on their marital status and the results are presented in the following Table 6.

Table 5. Income of the respondents.

\begin{tabular}{cccc}
\hline Income & Frequency & Percent & Cumulative Percent \\
\hline Up to Rs. 5000 & 09 & 11.25 & 11.25 \\
Rs. 5001 to 10,000 & 11 & 13.75 & 25.00 \\
Rs. 10,001 to 15,000 & 20 & 25.00 & 50.00 \\
Rs. 15,001 to 20,000 & 14 & 17.50 & 67.50 \\
Rs. 20,001 and above & 26 & 32.50 & 100.0 \\
Total & 80 & 100.0 & \\
\hline
\end{tabular}

Source: Primary data.

Table 6. Marital status of the respondents.

\begin{tabular}{cccc}
\hline Marital status & Frequency & Percent & Cumulative Percent \\
\hline Married & 51 & 63.75 & 63.75 \\
Unmarried & 29 & 36.25 & 100.00 \\
Total & 80 & 100.00 & \\
\hline
\end{tabular}

Source: Primary data. 
From Table 6, it is found that 63.75 percent of the married and 36.25 unmarried respondents prefer using JIO mobile network. Therefore maximum of married respondents among the total taken for the study prefer using JIO mobile network.

\subsection{Type of Scheme Utilized}

The JIO mobile network has formed two different schemes for the benefit of the customers to choose any thing based on their suitability. The following frequency table explains the most preferred scheme by the customers using JIO mobile network.

From the below Table 7, it is found that 70 percent of the respondents prefer using prepaid scheme and 30 percent prefer using post-paid schemes. Maximum of the respondents prefer prepaid scheme.

\subsection{Number of Years Using JIO Services}

The number of years the customers are using the JIO services in Vellore District explains the service quality efficiency and good network coverage. The following frequency Table 8 explains the number of years the customers are using JIO mobile network in Vellore District.

From the above table it is found that 42.50 percent of the respondents are using JIO services since last one year, 31.25 percent are using since last two years and above 26.25 percent are using this service less than a year. Therefore maximum of the respondents use 26.25 percent services less than a year.

\subsection{Number of Times Using Value Added Service}

The service organizations are making the Value-Added-Services as hot-spot for

Table 7. Type of scheme utilized.

\begin{tabular}{cccc}
\hline Type of scheme & Frequency & Percent & Cumulative Percent \\
\hline Prepaid & 56 & 70.00 & 70.00 \\
Post-paid & 24 & 30.00 & 100.00 \\
Total & 80 & 100.00
\end{tabular}

Source: Primary data.

Table 8. Number of years using JIO.

\begin{tabular}{cccc}
\hline Number of years & Frequency & Percent & Cumulative Percent \\
\hline Less than a year & 21 & 26.25 & 26.25 \\
One year & 34 & 42.50 & 68.75 \\
Two year and above & 25 & 31.25 & 100.00 \\
Total & 80 & 100.00 & \\
\hline
\end{tabular}

Source: Primary data. 
making profit. From the service providers' point of view the Value-Added-Services are providing excellent leverage. Exploiting a very insignificant marginal cost, the marginal profit accrued is really phenomenal at the satisfaction of the customer. The status of the Vale-Added-Services, which in turn echoes about the product favorite and client consummation, can be gauged through questions where options are spanning like the following in the questionnaire of the research: 1) Rare, 2) Often, 3) Frequent, 4) Regular and 5) Not regular.

It is analyzed from the below Table 9, that 30 percent of the respondents frequently use value added services, 26.25 percent use it often, 16.25 percent use it rarely, 15 percent use it regularly whereas 12.50 percent of the respondents are not regular is using value added services. Therefore Value added services are used frequently by the respondents.

\subsection{Consummation on the Current Service Provider}

The consummation, the subjective element in relative plane, is the facade of any business entity. However, the strategy evolved for consummation cannot be invoked for dissatisfaction universally. Both states of clients' psyche must be evaluated and met with different unique strategies. The following frequency table explains the level of satisfaction expressed by the customers towards JIO Mobile network.

From the below Table 10, it is found that 61.25 percent of the respondents expressed satisfaction towards their current service provider whereas 38.75 percent are not satisfied with their current service providers.

\subsection{Purpose of Uses of JIO Mobile}

The following frequency table explains the purpose which the customers using JIO mobile network.

It is analyzed from the below Table 11, that 22.50 percent of the respondents use JIO mobile for personnel purpose 33.75 use it for business, and 26.25 percent use it for office. Purpose whereas 17.50 percent use it for other purposes. Therefore maximum of the respondents use for personnel purposes.

Table 9. Number of times using value added services.

\begin{tabular}{cccc}
\hline Number of times & Frequency & Percent & Cumulative Percent \\
\hline Rarely & 13 & 16.25 & 16.25 \\
Often & 21 & 26.25 & 42.50 \\
Frequently & 24 & 30.00 & 72.50 \\
Regularly & 12 & 15.00 & 87.50 \\
Not regular & 10 & 12.50 & 100.0 \\
Total & 80 & 100.0 &
\end{tabular}

Source: Primary data. 
Table 10. Level of consummation.

\begin{tabular}{cccc}
\hline Level of satisfaction & Frequency & Percent & Cumulative Percent \\
\hline Yes & 49 & 61.25 & 61.25 \\
No & 31 & 38.75 & 100.00 \\
Total & 80 & 100.00 & \\
\hline
\end{tabular}

Source: Primary data.

Table 11. Purpose of uses.

\begin{tabular}{cccc}
\hline Purpose of uses & Frequency & Percent & Cumulative Percent \\
\hline Business & 27 & 33.75 & 33.75 \\
Office & 21 & 26.25 & 60.00 \\
Personnel & 18 & 22.50 & 82.50 \\
Others & 14 & 17.50 & 100.00 \\
Total & 80 & 100.0 & \\
\hline
\end{tabular}

Source: Primary data.

\section{Summary}

In fact, most of the behavioral studies have identified the significant differences between the opinion of male and female customers using JIO mobile network. From the sample taken for the study, it is found from the above tables that 60 Percent male respondents and 40 percent of females are using JIO mobile network. On the basis of the age, the customers using JIO mobile network are grouped under four heads, namely, below 20 years of age, 21 to 30 years, 31 to 40 years and above 40 years. In general Age of the respondents expose their maturity in understanding and selecting the best mobile network.

Maximum of 31.25 percent are graduates using JIO mobile network, 22.50 percent are postgraduates, 18.50 percent are higher secondary, and 12.50 percent are SSLS qualified. It is found that 32.50 percent of the respondents earning a monthly income of Rs. 20,001 above 25 percent earning Rs. 10,001 to Rs. 15,000 17.50 percent earning income between Rs. 15,001 to Rs. 20,000, 13.75 percent earning between Rs. 5001 to 10,000. 63.75 Percent of the married and 36.25 unmarried respondents prefer using JIO mobile network. 70 percent of the respondents prefer using prepaid scheme and 30 percent prefer using post-paid schemes.

Maximum of the respondents prefer prepaid scheme. 42.50 percent of the respondents are using JIO services since last one year, 31.25 percent are using since last two years. 30 percent of the respondents frequently use value added services. It is found that 61.25 percent of the respondents expressed satisfaction towards their current service provider. 22.50 percent of the respondents use JIO mobile for personnel purposes whereas 33.75 use it for business, and 26.25 percent use it for office purposes. 


\section{Findings}

On the basis of the age, the customers using JIO mobile network are grouped under four heads, namely, below 20 years of age, 21 to 30 years, 31 to 40 years and above 40 years.

* Only a minimum of 18.75 percent below 20 years prefer using JIO mobile network.

* Maximum of respondents using JIO mobile network are graduates in the study area.

* 23.75 percent of professionals, 21.25 percent self-employed, 10 percent of students prefer using JIO mobile network.

* Maximum of respondents earning a monthly income of Rs. 20,001 and above prefer this network.

* It is found that 63.75 Percent of the married and 36.25 unmarried respondents prefer using JIO mobile network.

* It is found that 70 percent of the respondents prefer using prepaid scheme.

* It is found that 31.25 percent of the respondents are using JIO mobile network since two years.

* 30 percent of the respondents frequently use value added services, 26.25 percent use it often.

* 22.50 percent of the respondents use JIO mobile for personnel purpose 33.75 use it for business, and 26.25 percent use it for office.

\section{Conclusion}

The growth rate of Indian mobile telephony marketplace has drastically increased with fast velocity in the last decade. Concerning the subscribers' base, call tariffs and favorable regulatory policies have led to a tremendous increase. Appropriate recognition of the client favorites will make easy the favorableness towards the various mobile service providers.

Incessant investigation on customers will improve the client consummation. The present study centered on the revise of client favorites with the particular orientation to the mobile system users in Vellore city. The study has been accepted out to locate out the majority favored mobile system overhaul supplier and the factors influencing to use the scrupulous mobile system service. The consequences exposed that Airtel, JIO and Idea are the good number preferential mobile system service suppliers.

The most influencing factors in the selection of a particular mobile network service provider are service quality, value added services and customer care services. If these propositions are measured by the individual mobile system service suppliers and it would positively assist to get better the service worth of the mobile system service suppliers and also it obtains better the level of consummation of the mobile system users.

\section{Suggestions}

JIO, Airtel, and Idea are the preferred networks of preponderance of the res- 
pondents in Vellore. For this reason it is not compulsory that the other service suppliers encompass to center on promoting their service superiority, receptiveness, good-looking proposes, client care service and impactful announcement in arrange to broaden their support and capture more clientele and marketplace share.

It is established from the study that the preponderance of the sample encompass known utmost preferred to the service quality. Service quality of the system plays a key function. For this reason it is not compulsory that the machinists encompass to uphold good service quality in the call connectivity, satisfying their anticipation, value added service obtainable by them counting mobile data, caller tune, dry run, playback etc. More than ever individual concentrations have to be agreed for as long as on time client care connectivity which may save client time and able to progression their demand by the service suppliers on a need basis.

\section{Conflicts of Interest}

The authors declare no conflicts of interest regarding the publication of this paper.

\section{References}

Abbas, M. (2021). Industry Need Support, Reduction in Levies-Reliance JIO's Top Executive. The Economic Times, $25^{\text {th }}$ February 2021.

Akroesh et al. (2010). An Empirical Model of Customer Satisfaction and Brand Preferences. International Journal of Marketing, 6, 76-101.

Ambani, M. (2020). Reliance JIO to Launch 5 G Network in Second Half of 2021. Business Standard, December 8, 2020 12:01 IST.

Jyothsna, M., \& Mahalakshmi, S. (2015). Customer Perception towards Mobile Operators. (A Study Undertaken in Visakhapatnam, Andhra Pradesh).

Mathiraj, S. P., Geeta, D. S. T., \& Saroja Devi, R. (2019). Customer Behaviour on Mobile Phone Network Portability Services. International Journal of Scientific \& Technology Research, 8, 2360-2366.

Vijay, P., \& Krishnaveni, V. (2017). A Study on Customers Satisfaction with Special Reference to Mobile Network Users in Coimbatore City. Journal of Advanced Research in Dynamical and Control System, 1, 104-111. 